\title{
Selenium-Functionalized Corn Starch as a Biodegradable GPx Mimic with High Catalytic Performance
}

\author{
Shufei Jiao ${ }^{1}$, Zijie Liu ${ }^{1}$, Min Liu ${ }^{1}$, Yongxian Liu ${ }^{2}$, Shuming Zhong ${ }^{1}$, Feng Wang ${ }^{1, *}$ and Yanzhen Yin ${ }^{1, *}$ \\ 1 School Petroleum and Chemical Engineering, Beibu Gulf University, Qinzhou 535011, China; \\ jiaoshufei2013@163.com (S.J.); fengye83818@163.com (Z.L.); minminliu1025@163.com (M.L.); \\ zsm_7104@163.com (S.Z.) \\ 2 Agricultural Resource and Environment Research Institute, Guangxi Academy of Agricultural Sciences, \\ Nanning 535007, China; liuyx@163.com \\ * Correspondence: fefe12138@163.com (F.W.); yinyanzhen@bbgu.edu.cn (Y.Y.); Tel.: +86-0777-280-7006 (Y.Y.); \\ Fax: +86-0777-280-8633 (Y.Y.)
}

Citation: Jiao, S.; Liu, Z.; Liu, M.; Liu, Y.; Zhong, S.; Wang, F.; Yin, Y. Selenium-Functionalized Corn Starch as a Biodegradable GPx Mimic with High Catalytic Performance. Polymers 2021, 13, 4309. https://doi.org/ 10.3390/polym13244309

Academic Editors: Tao-Hsing Chen and Shih-Chen Shi

Received: 9 November 2021

Accepted: 3 December 2021

Published: 9 December 2021

Publisher's Note: MDPI stays neutral with regard to jurisdictional claims in published maps and institutional affiliations.

Copyright: (c) 2021 by the authors. Licensee MDPI, Basel, Switzerland. This article is an open access article distributed under the terms and conditions of the Creative Commons Attribution (CC BY) license (https:/ / creativecommons.org/licenses/by/ $4.0 /)$.

\begin{abstract}
Selenium-functionalized starch (Se-starch80) is one of the main functional foods used for selenium supplementation. In traditional agriculture, Se-starch has some deficiencies such as long growth cycle and unstable selenium content that prevent its antioxidant performance. In this study, Se-starch was prepared by the nucleophilic addition between $\mathrm{NaSeH}$ and carbon-carbon double bond of octenyl succinic anhydride waxy corn starch ester (OSA starch). Some techniques such as ${ }^{1}$ HNMR, XPS, SEM-EDS, XRD and FT-IR were used to characterize the relevant samples and the results showed that the modification did not destroy the starch framework significantly and the catalytic center (negative divalent selenium) was anchored on the starch framework. The intensive distribution of catalytic center on the starch surface and the hydrophobic microenvironments derived from the OSA chains furnished the Se-starch80 with a high GPx-like catalytic activity (initial reaction rate $=3.64 \mu \mathrm{M} / \mathrm{min}$ ). This value was about $1.5 \times 10^{5}$ times higher than that of a typical smallmolecule GPx mimic (PhSeSePh). In addition, the Se-starch80, without any cytotoxicity, showed a saturated kinetic catalytic behavior that is similar to a typical enzyme. This work exemplifies a biodegradable selenium-functionalized polymer platform for the high-performing GPx mimic.
\end{abstract}

Keywords: OSA starch; selenium functionalization; GPxmimic; catalytic mechanism; cytotoxicity

\section{Introduction}

Selenium (Se) is an important trace element that participates in the synthesis of $25 \mathrm{Se}-$ containing proteins in the human body. Glutathione peroxidase (GPx), with the -SeH catalytic center, is a particularly important antioxidant enzyme that scavenges the excess free radicals in human body. GPx and therefore protects human against oxidative damage [1], inflammation [2], cancer [3], and Keshan disease [4,5]. As the continuous increase in health awareness and healthcare, it is widely concerned to obtain selenium-functionalized supplementation for maintaining the health [6-8]. In the traditional cultivation, Se-functionalized nutrients are mainly in the form of selenide protein deriving from wheat [9-11], rice [12-14], potato $[15,16]$, etc. Due to the low protein content in these crops and the complex and long growth period of plant, the selenium content is unstable in targeted products. To solve this problem, in the past decade, many GPx mimics such as small molecules [17,18], block copolymers [19,20], supramolecular materials [21], and nanomaterials [22] with stable selenium component have been designed and evaluated the antioxidant efficacy. However, most of these GPx mimics is limited in the application of food and drugs since their biotoxicity and poor biodegradability. Therefore, it is still a challenge to obtain biodegradable Se-functionalized supplements with stable selenium content.

Starch, one of the most important foods for human diet, is expected to be an ideal food source of selenium supplements. However, due to the limited metabolic process, 
the selenium-containing starch from natural plants is rarely found so far. Compared with protein, starch reveals a more stable structure in the chemical modifications. Sun et al. [23] synthesized a novel biodegradable starch-based hydrogel by using starch and Se-containing cross-linker. Such hydrogel revealed multi stimuli responsiveness property like enzyme hydrolysis and redox responsive cleavage, making it a promising biomedical candidate of controlled drug delivery. Kazemi et al. [24] prepared colloidal selenium nanoparticles in a starch matrix and showed its nontoxicity in colorectal cancer SW480 cell via the MTT assay. Moreover, the selenium nanoparticles encapsulated in a starch matrix (NC Se/St), as an effective and environmentally safe agent, revealed a targeted low-dose delivery to bacterial phytopathogens [25]. These studies indicated that the starch combined with selenium is biodegradable and safe in the medical application. Unfortunately, the Se-containing starch with GPx-like catalytic activity has not been synthesized and studied.

It is well-known that the octenyl succinic anhydride starch ester (OSA starch) is a typical modified starch with wide applications in foods and medicines [26,27]. In the OSA starch skeleton, the olefinic bond, as a reactive group, could react with sodium hydrogen selenide $(\mathrm{NaSeH})$ via the nucleophilic addition and generate the $-\mathrm{SeH}$. While the $-\mathrm{SeH}$ is the typical catalytic center of GPx [28]. Inspired by these, in this work, the OSA starch was firstly employed as the raw material to produce a biodegradable starchbased GPx mimic (Se-starch) via the reaction with NaSeH (Scheme 1). Simultaneously, the synthesis conditions, such as reaction time, reaction temperature, and the component of reactants were optimized to obtain the Se-starch with high catalytic activity. The structural characterizations of the samples were conducted in ${ }^{1} \mathrm{H}$ NMR, XPS, SEM-EDS, etc. The catalytic mechanism of Se-starch as a GPx mimic was also studied in vitro. In addition, a MTT assay was used to investigate the cytotoxicity of Se-starch. This study may provide a new method for preparing the Se-functionalized starch with high GPx-like catalytic activity.

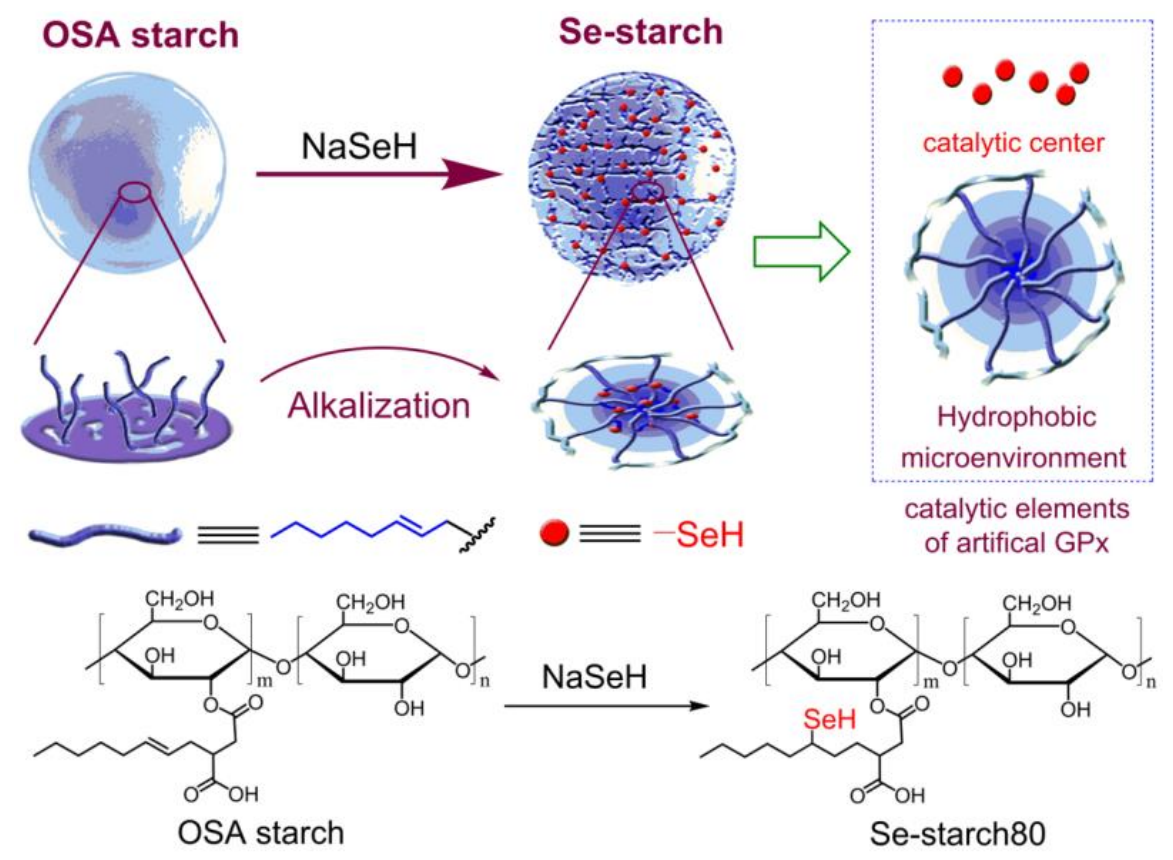

Scheme 1. The schematic illustration for preparing selenium-functionalized waxy corn starch.

\section{Materials and Methods}

\subsection{Materials}

Octenyl succinic anhydride waxy corn starch ester (OSA Starch, food grade) with a degree of substitution (DS) of 2.2\%, was purchased from Guangxi State Farms Mingyang Starch Development Co., Ltd., Nanning, China. Chemicals including cumene hydrogen peroxide $(\mathrm{CUOOH})$, hydrogen peroxide $\left(\mathrm{H}_{2} \mathrm{O}_{2}\right)$, selenium powder, sodium borohydride $(\mathrm{NaBH})$, and 4-nitrothiophenol (NBT) were purchased from J\&K Scientific, Ltd., San Jose, 
CA, USA. Ethanoland sodium hydroxidewere of analytical grade and purchased from Xilong Chemical Co., Ltd., Shantou, China. 3-Carboxy-4 nitrothiophenol (TNB) was synthesized according to the previously reported method [29]. Human hepatocellular carcinoma cell line HepG2 was obtained from Cell Bank of the Type Culture Collection Committee of the Chinese Academy of Sciences.

\subsection{Preparation of Selenium-Functionalized Waxy Corn Starch}

To obtain a NaSeH stock solution, equimolar amounts of Se powder and $\mathrm{NaBH}_{4}$ were added to a $100 \mathrm{~mL}$ flask, and then an appropriate amount of a mixed solvent of ethanol and $\mathrm{H}_{2} \mathrm{O}$ was slowly added into this flask under $\mathrm{N}_{2}$ atmosphere. This flask was held for $2 \mathrm{~h}$ at room temperature to get the $\mathrm{NaSeH}$ solution. OSA starch $(10.0 \mathrm{~g})$ and the mixture of ethanol and $\mathrm{H}_{2} \mathrm{O}(100 \mathrm{~mL}$ ) (the volume ratio of ethanol was $10 \%, 20 \%, 30 \%, 40 \%, 50 \%, 60 \%$, $70 \%, 80 \%$, and $90 \%$, respectively) were placed in a $250 \mathrm{~mL}$ flask and vigorously stirred for $30 \mathrm{~min}$. Then, a certain amount of $\mathrm{NaSeH}$ solution (the mole ratio of $\mathrm{NaSeH}$ to $-\mathrm{HC}=\mathrm{CH}-$ was $1: 1,1.2: 1,1.5: 1,1.8: 1$, and 2.2:1, respectively) was slowly added to the above solution in an ice bath, and the $\mathrm{pH}$ of the solution was adjusted to the range of 8-10 using $\mathrm{NaOH}$ solution $(0.1 \mathrm{M})$. Next, the flask was transferred to a water bath with different temperatures (30, 40, 50, 60, and $70^{\circ} \mathrm{C}$, respectively) for the reaction. After holding for the preset time (between 1 and $8 \mathrm{~h}$ ), the reaction was terminated by adjusting the solution $\mathrm{pH}$ to be about 3 using $0.1 \% \mathrm{HCl}$ solution. Then, ethanol (about $500 \mathrm{~mL}$ ) was added into the system over $20 \mathrm{~min}$ to precipitate the Se-starch. The starch precipitate was collected by a vacuum filter, and washed successively using $75 \%$ ethanol and anhydrous ethanol. Finally, the product was vacuum-dried at $50{ }^{\circ} \mathrm{C}$ for $24 \mathrm{~h}$.

\subsection{Characterizations of Se-Starch}

A Bruker Advance III HD $500 \mathrm{MHz}$ NMR spectrometer was used to record the ${ }^{1} \mathrm{HNMR}$ spectra of the related samples that were dissolved in $\mathrm{D}_{2} \mathrm{O}$. Fourier-transform infrared (FTIR) spectra were collected using a Frontier FT-IR spectrometer (Perkin Elmer) with the attenuated total reflection mode. The scan range of wavenumber was $500-4000 \mathrm{~cm}^{-1}$. The scanning electron microscopy (SEM, 6700F, JEOL) and energy-dispersive $\mathrm{X}$-ray spectrometry (EDS) for the Se-starch samples were performed on a 6700F microscope (JEOL). A D8 ADVANCE $X$-ray diffractometer ( $\mathrm{Cu}-\mathrm{K} \alpha$ radiation, $\lambda=0.154 \mathrm{~nm}$; Bruker) was employed to collect the X-ray diffraction (XRD) patterns of the samples over a $2 \theta$ range from 5 to $40^{\circ}$, with a tube voltage of $40 \mathrm{kV}$ and a tube current of $40 \mathrm{~mA}$. A Thermo fisher Scientific K-Alpha XPS spectrometer (Mono $\mathrm{Al} \mathrm{K \alpha}\left(h_{\mathrm{v}}=1486.6 \mathrm{eV}\right.$ ), X-ray source of $72 \mathrm{~W}$, wide-scan and high resolution spectra of $100.0 \mathrm{eV}$ and $40 \mathrm{eV}$, set the $\mathrm{C} 1$ s peak to $284.6 \mathrm{eV}$ ) was employed to analyze elemental compositions and the selenium form. The Se content of Se-starch was determined using an atomic fluorescence spectrometer (AFS-9530, Beijing Haiguang). The fluorescence spectra of the pyrene-containing samples were recorded on a fluorescence spectrophotometer (Agilent Cary Eclipse) with the excitation wavelength of $335 \mathrm{~nm}$.

\subsection{Determination of the Catalytic Activity of Se-Starch}

The catalytic activity of sample was determined according to the method reported by Wu and Hilvert [30], using NBT or TNB as an alternative of glutathione (GSH). In a typical test, $700 \mu \mathrm{L}$ of phosphate buffer (PBS, $\mathrm{pH}=7.0$ ), $100 \mu \mathrm{L}$ of Se-starch dispersion, and $100 \mu \mathrm{L}$ of NBT or TNB solution $(1.5 \mathrm{mM})$ were added into a quartz cuvette. The mixture in the quartz cuvette was uniformly pre-incubated for $2 \mathrm{~min}$ at room temperature. Then, the enzymatic reaction was initiated by adding $100 \mu \mathrm{L}$ of $\mathrm{CUOOH}$ or $\mathrm{H}_{2} \mathrm{O}_{2}(2.5 \mathrm{mM})$ as the substrates. The decrease in the absorption at $410 \mathrm{~nm}$ was monitored by an UV spectrophotometer (UV2600, Shimadzu). The catalytic activity (namely the antioxidant 
performance) of Se-starch was expressed by the initial reaction rate $\left(v_{0}, \mu \mathrm{M} / \mathrm{min}\right)$ of the enzymatic reaction, which was calculated by the following equation,

$$
v_{0}=\frac{\Delta \mathrm{A}}{\varepsilon \times \mathrm{L} \times \Delta \mathrm{t}}
$$

where $\Delta \mathrm{t}$ is the time of the enzymatic reaction from initiation to termination; $\Delta \mathrm{A}$ is the change of the absorbance during the enzymatic reaction within $\Delta \mathrm{t} ; \varepsilon$ is the molar extinction coefficient of NBT or TNB $\left(\varepsilon_{(\mathrm{NBT})}=14,6001 / \mathrm{M} \cdot \mathrm{cm}, \varepsilon_{(\mathrm{TNB})}=13,6001 / \mathrm{M} \cdot \mathrm{cm}, \mathrm{pH}=7.0\right)$; $\mathrm{L}$ is the optical path length of the quartz cuvette $(\mathrm{L}=1 \mathrm{~cm})$. Triplicates experiments were conducted to get the average $v_{0}$.

$$
\begin{gathered}
v_{0}=\frac{v_{0}[\mathrm{~S}]}{[\mathrm{S}]+K_{m}} \\
\frac{1}{v_{0}}=\left(\frac{K_{m}}{v_{\max }}\right) \frac{1}{[\mathrm{~S}]}+\frac{1}{v_{\max }}
\end{gathered}
$$

According to the Michaelis and Menten equation (Equation (2)) and double reciprocal plot (Equation (3)), the Michaelis constant $\left(K_{\mathrm{m}}, \mu \mathrm{M}\right)$ and the maximum reaction rate $\left(v_{\max }, \mu \mathrm{M} / \mathrm{min}\right)$ are determined using the Linear-regression curve by plotting $1 / v_{0}$ against $1 /[\mathrm{S}]$, in which the intercept is $1 / v_{\max }$ and the intercept is the absolute value of $1 / K_{\mathrm{m}}$. The [S] is the concentration of substrate [31].

$$
K_{\text {cat }}=v_{\max } /[\mathrm{E}]
$$

The reaction constant $\left(K_{\mathrm{cat}}, 1 / \mathrm{min}\right)$ was calculated using Equation (4), where the [E] is the concentration of enzyme.

\subsection{Cell Viability Assays}

MTT [3-(4,5-dimethylthiazol-2-yl)-2,5-diphenyltetrazolium bromide] assay was used to measure the cytotoxicity of Se-starch 80 toward HepG2 cells according to the previously reported literature [32]. The density of cell was $2 \times 10^{5}$ cells per well. The concentration of the Se-starch 80 for incubating the cell varied from 10 to $1000 \mu \mathrm{g} / \mathrm{mL}$. The optical density was measured using a microplate reader (PerkinElmer Victor X5) at $490 \mathrm{~nm}$. The relative cell viability was depicted as the percentage relative to the optical density derived from the control test.

\section{Results and Discussion}

\subsection{Preparation and Structural Characterization of Se-Starch 80}

In this work, as shown in Scheme 1, thecatalytic center (-SeH) was directly introduced into the OSA starch via the nucleophilic addition between $\mathrm{NaSeH}$ and the $-\mathrm{HC}=\mathrm{CH}-$ in OSA starch. According to the optimization of preparation process for the selenium-functionalized starch (presented later in this work), the Se-starch (Se-starch80) that was produced under the conditions of volume ratio of ethanol $80 \%$, temperature $30^{\circ} \mathrm{C}$, $\mathrm{n}_{(\mathrm{NaSeH})}: \mathrm{n}_{\text {(alkene) }}=1.5: 1$ and reaction time $6 \mathrm{~h}$ revealed the highest catalytic activity. Such Se-starch with the Se content of $0.033 \mathrm{mg} / \mathrm{kg}$ was selected for the characterizations.

In order to determine the selenization reaction mechanism, the ${ }^{1} \mathrm{H}$ NMR spectroscopy was used to characterize the changes of OSA starch during the reaction. As shown in Figure 1, for the OSA starch, the ${ }^{1} \mathrm{H}$ NMR spectrum showed a proton signal peak at $5.25 \mathrm{ppm}$, which was ascribed the proton of $-\mathrm{HC}=\mathrm{CH}-$ in the OSA chains [33]. This peak almost disappeared in the ${ }^{1} \mathrm{H}$ NMR spectrum of Se-starch80, suggesting the $-\mathrm{HC}=\mathrm{CH}-$ participated in the reaction. In this reaction system, $\mathrm{NaSeH}$ is a strong nucleophile that can undergo a reaction similar to the $-\mathrm{SH}$ and $-\mathrm{HC}=\mathrm{CH}-$ groups [34]. While the $-\mathrm{HC}=\mathrm{CH}-$ is the group with the maximum reactivity in the OSA starch toward NaSeH. Therefore, it could be concluded that the nucleophilic addition reaction occurred between $\mathrm{NaSeH}$ and $-\mathrm{HC}=\mathrm{CH}-$, resulting in the disappearance of the proton signal of $-\mathrm{HC}=\mathrm{CH}-$. The 
selenium in the Se-starch 80 was confirmed using XPS, as shown in Figure 2A. The peaks located at 531, 497, 285 and $54 \mathrm{eV}$ were assigned to oxygen, sodium, carbon, and selenium signal, respectively. In the locally magnified image, the $\mathrm{Se}\left(3 \mathrm{~d}_{3 / 2,5 / 2}\right)$ signal peak appeared at about $54 \mathrm{eV}$, indicating the negative bivalent selenium $\left(\mathrm{Se}^{2-}\right)$ in the Se-starch [35]. Generally, $\mathrm{NaSeH}$ can be easily oxidized by $\mathrm{O}_{2}$ to form the red nano $\mathrm{Se}^{0}$. However, the Se-starch was white, which further proved that the - SeH was covalently bonded to the starch skeleton, rather than being presented as elemental selenium, which is usually gray or red [36]. Furthermore, the EDS results for Se-starch 80 showed that the Se was evenly distributed on the surface of the starch particles with a content of $3 \mathrm{wt} \%$ (Figure 2B). This content is significantly greater than that of the value determined by AFS $(0.033 \mathrm{mg} / \mathrm{kg}$, $3.3 \times 10^{-6} \mathrm{wt} \%$ ). These results suggested that the anchored - SeH was mainly distributed on the surface of starch, which would profit the exposure of the active center for catalytic reaction.

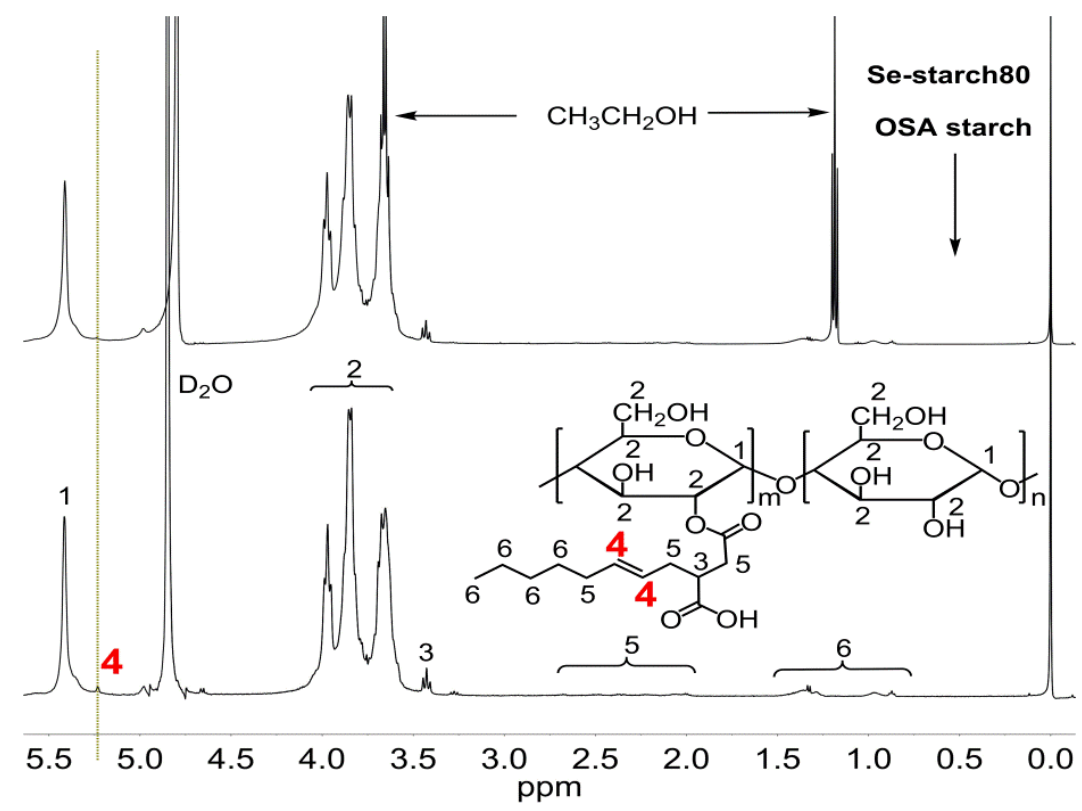

Figure 1. ${ }^{1} \mathrm{H}$ NMR spectra of OSA starch and Se-starch80 in $\mathrm{D}_{2} \mathrm{O}$.

The OSA starch granule showed a smooth surface (Figure 2C), while a rough surface with grooves was observed in the Se-starch80 (Figure 2D). This morphology change of the starch during the modificationmight be due to the $\mathrm{NaSeH}$, a strong alkali would gelatinize or destruct the starch [37]. The FT-IR spectrum of Se-starch80 presented the characteristic peaks at $3440 \mathrm{~cm}^{-1}$ (O-H stretching), $2930 \mathrm{~cm}^{-1}$ (C-H stretching) [38,39], $1652 \mathrm{~cm}^{-1}$ ( $\mathrm{C}=\mathrm{O}$ stretching), $1021 \mathrm{~cm}^{-1}$ (C-O stretching) [40]. These peaks were almost identical to that of OSA starch (Figure 3A). However, the intensity of the $\mathrm{O}-\mathrm{H}$ stretching (partially relevant to the bound water) for Se-starch 80 was lower than that of the OSA starch. One probable explanation is that the outer portion of starch was gelatinized by the $\mathrm{NaSeH}$ solution, resulting in a decrease of bound water on the starch surface [41]. In addition, the dehydration of starch by reaction medium with high ethanol content might be the other cause of the decrease of $\mathrm{O}-\mathrm{H}$ stretching. The structure change for starch during the modification was further studied by XRD (Figure 3B). The XRD pattern for Se-starch80 with a diffraction peak at about $19.4^{\circ}$ was similar to that of OSA starch, indicating that the Se-functionalized reaction mainly arose on the surface of starch and did not dramatically damage the internal skeleton of starch [41]. 

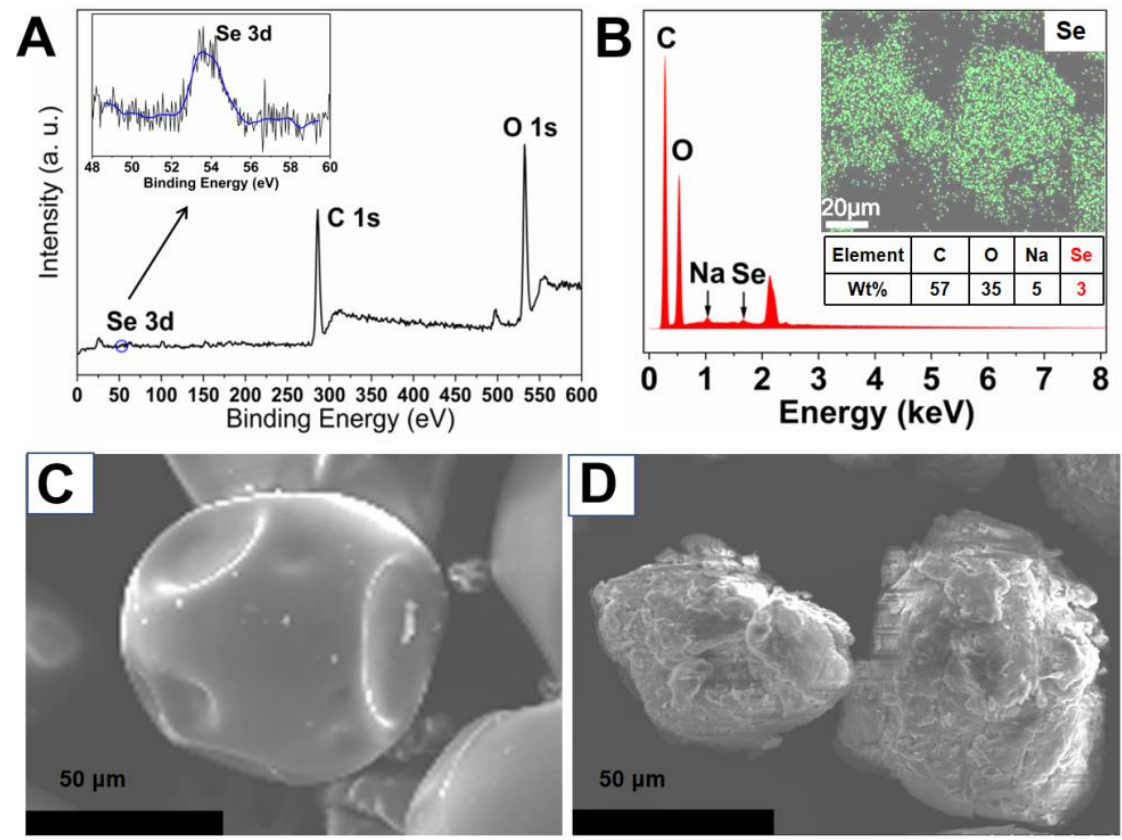

Figure 2. XPS spectrum (A), EDS spectrum and Se map of Se-starch80 (B); SEM images of OSA starch (C) and Se-starch80 (D).
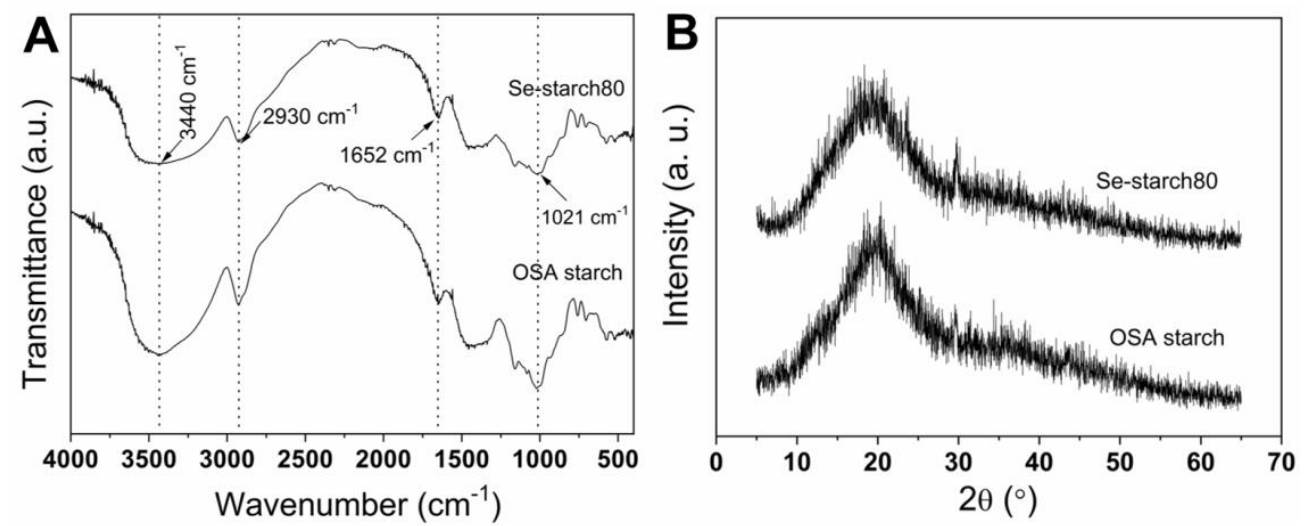

Figure 3. FT-IR spectra (A) and XRD patterns (B) of OSA starch and Se-starch80.

\subsection{Optimization of the Preparation Process of Se-Starch}

Similar to natural enzymes, the catalytic activity of GPx mimic may be greatly affected by structural changes in their skeleton, catalytic center, and peripheral recognition [12,24]. For the Se-starch, the starch provided a degradable framework with - SeH as the catalytic center, and formed a coarse surface with grooves, which was similar to the natural GPx. In addition, the OSA molecular chains offered the Se-starch surface with hydrophobic microenvironment, which could also influence the catalytic activity. These factors would be affected by the reaction condition. Therefore, the effect of the reaction conditions including reaction time, reaction temperature, $\mathrm{n}_{(\mathrm{NaSeH})}: \mathrm{n}_{(-\mathrm{HC}=\mathrm{CH}-)}$, and volume ratio of ethanol $(\mathrm{V} \%)$ on the Se content and catalytic activity $\left(v_{0}, \mu \mathrm{M} / \mathrm{min}\right)$ were investigated. The NBT and CUOOH were used as the substrates to test the $v_{0}$. Figure $4 \mathrm{~A}$ shows the effect of reaction time on the Se content and $v_{0}$ under the conditions of reaction temperature $40{ }^{\circ} \mathrm{C}, \mathrm{n}_{(\mathrm{NaSeH})}: \mathrm{n}_{(-\mathrm{HC}=\mathrm{CH}-)}=1: 1$ and volume ratio of ethanol $30 \%$. The $v_{0}$, similar to the Se content, increased with the prolongation of reaction time in the initial stage of $6 \mathrm{~h}$. Due to the equilibrium of reaction, the further increase of reaction time did not promote the $v_{0}$ and the Se content significantly. Therefore, the reaction time of $6 \mathrm{~h}$ was selected for preparing Se-starch. 

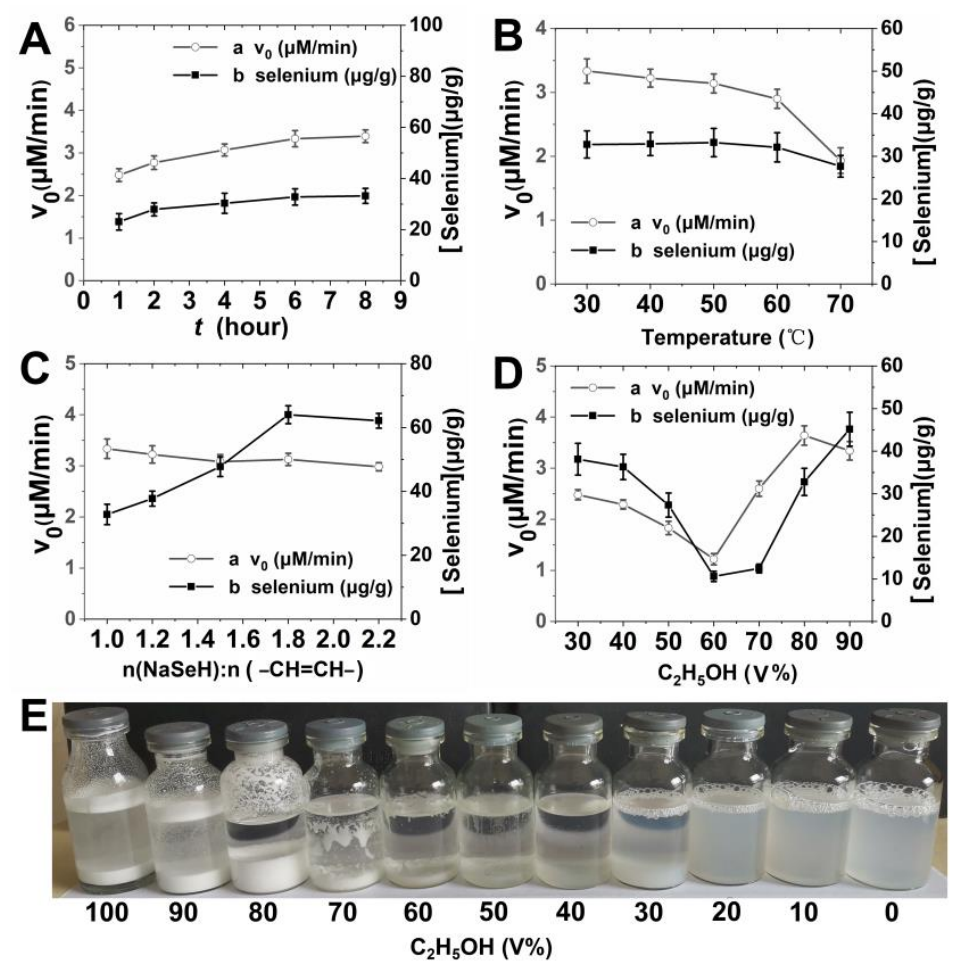

Figure 4. The $v_{0}$ and the selenium content as the function of reaction time (A), reaction temperature (B), the mole ratio of $\mathrm{NaSeH}$ and $-\mathrm{HC}=\mathrm{CH}-(\mathbf{C})$, and volume ratio of ethanol (D); the digital photographs of the reaction system with different volume ratio of ethanol (E).

The effect of reaction temperature on the Se content and $v_{0}$ under the conditions of reaction time $6 \mathrm{~h}, \mathrm{n}_{(\mathrm{NaSeH})}: \mathrm{n}_{(-\mathrm{HC}=\mathrm{CH}-)}=1: 1$, and volume ratio of ethanol $30 \%$ was conducted by altering the temperature from 30 to $70{ }^{\circ} \mathrm{C}$ (Figure $4 \mathrm{~B}$ ). The Se content almost did not changed at the temperature range from 30 to $60^{\circ} \mathrm{C}$, while dropped remarkably at $70{ }^{\circ} \mathrm{C}$. A possible explanation is that the reverse reaction of the nucleophilic addition reaction was dominant at high temperature. For the $v_{0}$, it decreased slightly as the temperature increased from 30 to $60^{\circ} \mathrm{C}$ and declined significantly at $70^{\circ} \mathrm{C}$. The reduction of $v_{0}$ would attribute to the decrease of Se. The partial gelatinization of the starch at high temperature would cover the Se active center, which might be the other reason for the decrease of $v_{0}$. Therefore, the nucleophilic addition reaction between $\mathrm{NaSeH}$ and OSA starch was performed at $30{ }^{\circ} \mathrm{C}$. The influence of the $\mathrm{NaSeH}$ content on the reaction was studied by changing the $\mathrm{n}_{(\mathrm{NaSeH})}: \mathrm{n}_{(-\mathrm{HC}=\mathrm{CH}-)}$ from 1.0 to 2.2 at the conditions of reaction time $6 \mathrm{~h}$, reaction temperature $30{ }^{\circ} \mathrm{C}$, and volume ratio of ethanol $30 \%$. As shown in Figure $4 \mathrm{C}$, the Se content increased with the increase of the molar ratio of $\mathrm{NaSeH}$ and $-\mathrm{HC}=\mathrm{CH}-$, whereas the $v_{0}$ did not change significantly as the molar ratio of $\mathrm{NaSeH}$ and $-\mathrm{HC}=\mathrm{CH}-$ increased. This result might be ascribed to the partial gelatinization of starch by alkaline $\mathrm{NaSeH}$, which coated the Se active center and hindered its catalysis. Although the high content of $\mathrm{NaSeH}$ could promote the Se content of Se-starch, the excessive $\mathrm{NaSeH}$ resulted in a troublesome purification of the product. Therefore, the molar ratio of $\mathrm{NaSeH}$ and $-\mathrm{HC}=\mathrm{CH}-$ was set to be 1.5 for the further experiments.

Figure $4 \mathrm{D}$ reveals the effect of volume ratio of ethanol $(\mathrm{V} \%)$ on the Se content and $v_{0}$ under the conditions of reaction time $6 \mathrm{~h}$, reaction temperature $30{ }^{\circ} \mathrm{C}$, and $\mathrm{n}_{(\mathrm{NaSeH})}: \mathrm{n}_{(-\mathrm{HC}=\mathrm{CH}-)}=1.5: 1$. At the low volume ratio of ethanol (such as $\mathrm{V} \%=0,10$, and $20 \%$ ), the OSA starch was completely emulsified and dispersed in the solution, resulting in a difficulty for separating the products from the solution (Figure $4 \mathrm{E}$ ). The increase of the $\mathrm{V} \%$ from $30 \%$ to $60 \%$ caused the aggregation of the soluble OSA starch, forming a bulk precipitation with high adhesion. This cohesive precipitation with limited reactive site to be exposed would restrict the nucleophilic addition reaction, resulting in a low Se content and catalytic activity. As the 
further increase of the V\%, the OSA starch particles could be dispersed freely in the reaction system, which benefited the heterogeneous reaction between $\mathrm{NaSeH}$ and OSA starch and consequently caused the increase of the Se content as well as the $v_{0}$. The decline of the $v_{0}$ at $\mathrm{V} \%=90 \%$ might be due to the dehydration of starch by ethanol, which could compact the starch to decrease the exposure of catalytic center. In addition, the change of the surface property of starch by dehydration might be the other reason of the decline of the $v_{0}$ at $\mathrm{V} \%=90 \%$. Therefore, the optimized volume ratio of ethanol for the reaction system was $80 \%$. Taken together, the optimized reaction conditions for preparing Se-starch were as follow: reaction time $6 \mathrm{~h}$, temperature $30^{\circ} \mathrm{C}$, molar ratio of $\mathrm{NaSeH}$ to $-\mathrm{HC}=\mathrm{CH}-1.5$ and volume ratio of ethanol 80\%, in which the targeted Se-starch (Se-starch80) revealed a high catalytic activity $\left(v_{0}=3.64 \mu \mathrm{M} / \mathrm{min}\right)$. This value is $1.5 \times 10^{5}$ times higher than the catalytic activity of a typical small-molecule GPx mimic (PhSeSePh) at the reaction system of NBT and $\mathrm{CUOOH}$.

\subsection{Catalytic Mechanism and Catalytic behavior of Se-Starch 80}

In general, the combinations with different substrates were used to analyze the effect of the hydrophobic interaction and the substrate recognition sites between substrates and the catalyst $[42,43]$. As the typical substrate, 4-nitrothiophenol (NBT, a hydrophobic substrate) and 3-carboxy-4-nitrothiophenol (TNB, a hydrophilic substrate) were used as the reductive thiophenol substrates, while $\mathrm{H}_{2} \mathrm{O}_{2}$ and $\mathrm{CUOOH}$ were used as the hydroperoxide substrates. $\mathrm{H}_{2} \mathrm{O}_{2}$ is more hydrophilic than the $\mathrm{CUOOH}$ for the absence of the p-cumyl group in $\mathrm{H}_{2} \mathrm{O}_{2}$. These substrate combinations were employed to test the catalytic activity of Se-starch80 (Scheme 2), in which the concentrations of thiophenol substrate and hydroperoxide substrate were $150 \mu \mathrm{M}$ and $250 \mu \mathrm{M}$, respectively. As shown in Table 1, Se-starch 80 revealed different $v_{0}$ at the reaction systems with various substrates. In the system containing both hydrophobic substrates $(\mathrm{NBT}+\mathrm{CUOOH})$, Se-starch80 exhibited the highest $v_{0}$, while it showed the minimumv $v_{0}$ in the system of TNB and $\mathrm{H}_{2} \mathrm{O}_{2}$, two hydrophilic substrates. These results suggested that the hydrophobic interaction played an important role in the catalysis. The hydrophobic microenvironments in the Se-starch 80 were testified by the pyrene fluorescence probe experiment [44] (Figure 5). The pyrene solution $\left(C=1.0 \times 10^{-6} \mathrm{M}\right)$ revealed a fluorescence intensity ratio $\left(\mathrm{I}_{1} / \mathrm{I}_{3}\right.$, the indicator of hydrophobicity) of 1.81 at peak $1(372 \mathrm{~nm})$ and peak $3(383 \mathrm{~nm})$. However, the solution containing pyrene (concentration $=1.0 \times 10^{-6} \mathrm{M}$ ) and Se-starch80 with a lower $\mathrm{I}_{1} / \mathrm{I}_{3}$ of 1.66 , indicating the formation of hydrophobic microenvironments in the Se-starch80 for gathering pyrene molecule [45]. The OSA starch, without $-\mathrm{SeH}$, did not present any catalytic activity in the system of NBT $+\mathrm{CUOOH}$, suggesting the key function of Se in the catalysis. In the system of TNB $+\mathrm{CUOOH}$, the $v_{0}$ of Se-starch 80 was comparable to that of Micellar Catalyst (Table 1), a previously reported GPx mimic with high catalytic activity [46].

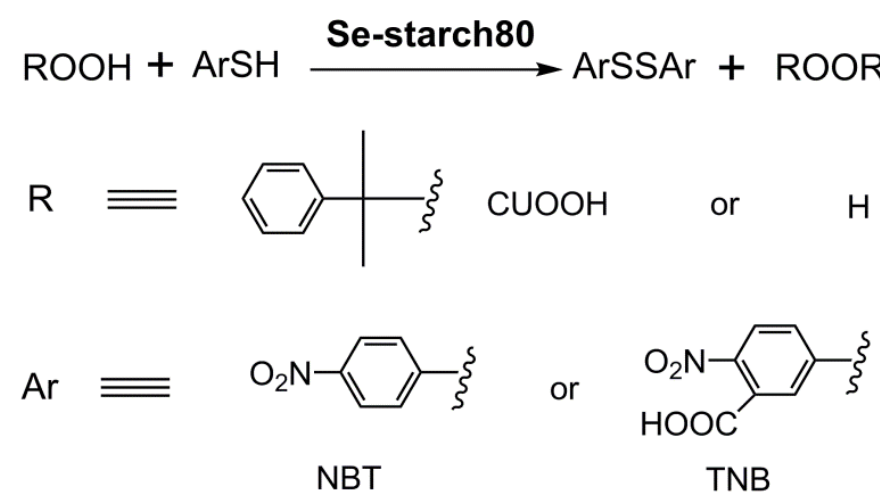

Scheme 2. The reaction between thiophenol substrates and hydroperoxide substrates under catalysis of Se-starch 80 . 
Table 1. The initial rates $\left(v_{0}\right)$ for the reduction of $\mathrm{ROOH}(250 \mu \mathrm{M})$ by $\mathrm{ArSH}(150 \mu \mathrm{M})$ in the presence of Se-starch 80 at $25^{\circ} \mathrm{C}$ and $\mathrm{pH} 7.0$ (50 mM PBS).

\begin{tabular}{cccc}
\hline Catalyst & ArSH & ROOH & $\boldsymbol{v}_{\mathbf{0}}(\boldsymbol{\mu M} / \mathbf{m i n})^{\mathbf{a}}$ \\
\hline PhSeSePh & NBT & $\mathrm{CUOOH}$ & $2.38 \times 10^{-5}$ \\
Micellar Catalyst & TNB & $\mathrm{CUOOH}$ & $2.25 \pm 0.24[41]$ \\
OSA starch & NBT & $\mathrm{CUOOH}$ & $\mathrm{ND}^{\mathrm{b}}$ \\
Se-starch80 & TNB & $\mathrm{CUOOH}$ & $2.11 \pm 0.17$ \\
Se-starch80 & TNB & $\mathrm{H}_{2} \mathrm{O}_{2}$ & $1.58 \pm 0.09$ \\
Se-starch80 & NBT & $\mathrm{CUOOH}$ & $3.64 \pm 0.19$ \\
Se-starch80 & NBT & $\mathrm{H}_{2} \mathrm{O}_{2}$ & $2.69 \pm 0.18$ \\
\hline
\end{tabular}

${ }^{\mathrm{a}}$ Main $\pm \mathrm{SD}$, each sample was measured for three times, and the $v_{0}$ was calculated on the basis of $1.0 \mu \mathrm{M}$ selenium monomer; ${ }^{b} \mathrm{ND}$, not detected.

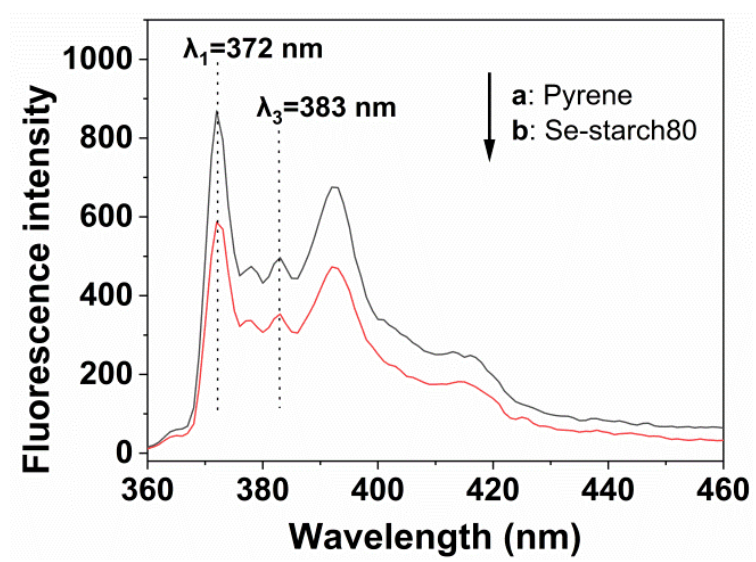

Figure 5. Fluorescence spectra of pyrene solution and the pyrene/Se-starch80 solution, where the concentration of pyrene was $1.0 \times 10^{-6} \mathrm{M}$.

The catalytic behavior of Se-starch80 was further investigated by changing the concentration of hydroperoxide substrates at the system containing the thiophenol substrates $(0.15 \mathrm{mM})$. As shown in Figure 6, for all substrate combinations, the catalytic activity of Sestarch 80 increased with the rise of the concentration of hydroperoxide substrates and then arrived at the equilibrium, suggesting a saturation kinetic catalytic behavior. This catalytic behavior was similar to a typical catalytic behavior of enzyme. Based on the profiles of $v_{0}$ versus the concentrations of hydroperoxide substrates, some catalytic kinetic parameters such as the maximum reaction rate $\left(v_{\max }, \mu \mathrm{M} / \mathrm{min}\right)$, the reaction constant $\left(K_{\mathrm{cat}}, 1 / \mathrm{min}\right)$, Michaelis-Menten constant $\left(K_{\mathrm{m}}, \mu \mathrm{M}\right)$, and the catalytic efficiency $\left(K_{\text {cat }} / K_{\mathrm{m}}, 1 / \mathrm{M} \cdot \mathrm{min}\right)$ were calculated and listed in Table 2 . The $K_{\mathrm{m}}$, an index of the affinity between catalyst and substrates, designates the concentration of substrate at $v=0.5 v_{\max }$, where $v$ is the reaction rate. A lower $K_{m}$ indicates a stronger affinity between catalyst and substrates. Taking the reaction system of $\mathrm{CUOOH}+\mathrm{TNB}$ and the system of $\mathrm{CUOOH}+\mathrm{NBT}$ as the comparison, the $K_{\mathrm{m}}$ of Se-starch 80 at the system of $\mathrm{CUOOH}+\mathrm{TNB}$ is inferior to the $K_{\mathrm{m}}$ derived from the system of $\mathrm{CUOOH}+\mathrm{NBT}$, indicating that Se-starch80 revealed a higher affinity to NBT than TNB. The higher affinity for TNB could be due to the bearing of - $\mathrm{COOH}$, which could interact with the hydroxyl of starch via hydrogen bond. However, the catalytic activity $\left(v_{0}\right)$ and the catalytic kinetic parameters including $v_{\max }, K_{\text {cat }}$, and $K_{\text {cat }} / K_{\mathrm{m}}$ of Se-starch80 in the system of $\mathrm{CUOOH}+\mathrm{TNB}$ were smaller than that in the system of CUOOH $+\mathrm{NBT}$. A possible explanation was that the strong affinity of Se-starch80 toward TNB resulted in a poor dissociation of the substrate from catalyst after catalytic reaction. The active centers in the catalyst were occupied by the bonded substrates, which hindered the subsequent reaction and consequently decreased the catalytic activity of Se-starch 80. 

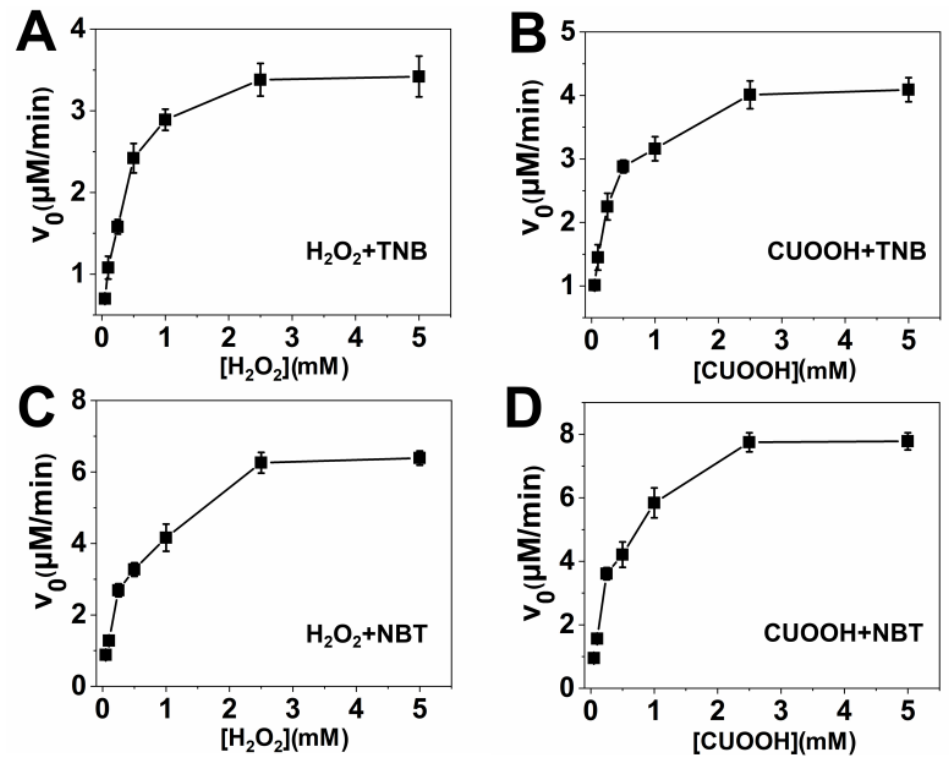

Figure 6. The initial rates as the function of concentration of hydroperoxide substrates at various reaction systems, $\mathrm{H}_{2} \mathrm{O}_{2}+\mathrm{TNB}(\mathbf{A}), \mathrm{CUOOH}+\mathrm{TNB}(\mathbf{B}), \mathrm{H}_{2} \mathrm{O}_{2}+\mathrm{NBT}(\mathbf{C})$, and CUOOH + NBT (D).

Table 2. The catalytic saturation kinetic constants of Se-starch80 in different reaction systems.

\begin{tabular}{ccccc}
\hline Substrates & $\begin{array}{c}\boldsymbol{v}_{\max } \\
(\boldsymbol{\mu} \mathbf{M} / \mathbf{m i n})\end{array}$ & $\begin{array}{c}\boldsymbol{K}_{\text {cat }} \\
(\mathbf{1} / \mathbf{m i n})\end{array}$ & $\begin{array}{c}\boldsymbol{K}_{m} \\
\boldsymbol{\mu M}\end{array}$ & $\begin{array}{c}\boldsymbol{K}_{\text {cat }} / \boldsymbol{K}_{m} \\
(\times \mathbf{1 0} \mathbf{5} / \mathbf{M} \cdot \mathbf{m i n})\end{array}$ \\
\hline $\mathrm{CUOOH}+\mathrm{NBT}$ & 7.94 & 15.88 & 750.79 & 2.11 \\
$\mathrm{H}_{2} \mathrm{O}_{2}+\mathrm{NBT}$ & 5.55 & 11.10 & 558.89 & 1.99 \\
$\mathrm{CUOOH}+\mathrm{TNB}$ & 3.75 & 7.50 & 281.65 & 2.66 \\
$\mathrm{H}_{2} \mathrm{O}_{2}+\mathrm{TNB}$ & 3.24 & 6.48 & 373.46 & 1.73 \\
\hline
\end{tabular}

\subsection{Cytotoxicity of Se-Starch80}

The exposure of Se-starch80 to the proliferation of HepG2 cancer cells was conducted to test the cells growth in a concentration-dependent manner (Figure 7). For all Se-starch80 concentrations in the media $(10-1000 \mathrm{~g} / \mathrm{mL})$, the HepG2 cell viability was marginally greater than $100 \%$, suggesting the facilitation of cell proliferation by Se-starch 80 . This result might be attributed to the antioxidative activity of Se-starch 80 as a GPx mimic. Overall, the Se-starch80, without any cytotoxicity, promoted the cell growth, suggesting that the biodegradable selenium-functionalized corn starch may be a good candidate for antioxidant enzyme mimic [23,47].

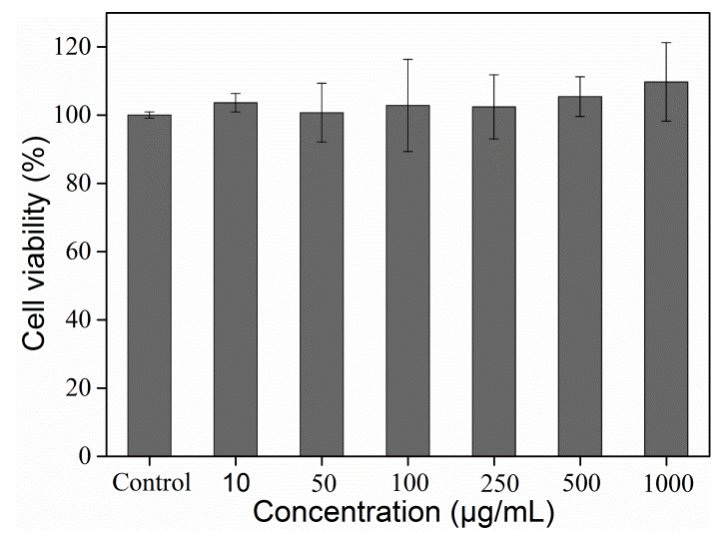

Figure 7. The cell viability as the function of the concentration of Se-starch80. 


\section{Conclusions}

In this paper, a new strategy for producing the Se-functionalized starch with GPx-like catalytic activity was developed by the nucleophilic addition between $\mathrm{NaSeH}$ and OSA waxy corn starch. The covalently linked $-\mathrm{SeH}$ on the starch surface provided it with catalytic centers, while the OSA chains supplied the hydrophobic microenvironments for gathering substrates. The optimal technological conditions for preparing Se-functionalized starch were that reaction time $6 \mathrm{~h}$, temperature $30^{\circ} \mathrm{C}$, molar ratio of $\mathrm{NaSeH}$ to $-\mathrm{HC}=\mathrm{CH}-$ 1.5 and volume ratio of ethanol $80 \%$. Such Se-functionalized starch with a Se content of $0.033 \mathrm{mg} / \mathrm{kg}$ revealed a high capacity for catalyzing the reaction between CUOOH and NBT $\left(v_{0}=3.64 \mu \mathrm{M} / \mathrm{min}\right)$. The high catalytic activity of Se-functionalized starch was attributed to the intensive distribution of catalytic center on the surface of starch and the hydrophobic microenvironments. The Se-functionalized starch did not require any bioconversion to perform the GPx-like function and showed a typical saturated kinetic catalytic behavior. In addition, the biodegradable starch skeleton did not change significantly during the modification and such Se-functionalized starch had no toxicity to cells. Therefore, a nontoxic Se-starch was prepared by a chemical modified method, which is expected to become a novel supplement with GPx-like activity for solving the nutrient deficiency of selenium. This work may provide a potential for the preparation of Se-functionalized starch.

Author Contributions: Conceptualization, S.J. and Y.Y.; methodology, Z.L.; software, S.J. and F.W.; validation, Y.Y. and M.L.; formal analysis, Y.Y. and M.L.; investigation, Y.Y. and Y.L.; resources, Y.Y.; data curation, Y.Y.; writing—original draft preparation, Y.Y.; writing—review and editing, F.W. and S.Z.; visualization, Y.Y.; supervision, Y.Y. and Y.L.; project administration, Y.Y.; funding acquisition, Y.Y. All authors have read and agreed to the published version of the manuscript.

Funding: This research was funded by the National Natural Science Foundation of China, grant number 51663020; Natural Science Foundation for Distinguished Young Scholars of Guangxi Province, grant number 2017GXNSFFA198007; and Project of Guangxi Colleges and Universities for the Promotion of Foundation Ability of Young Teachers, grant number2021KY0436.

Institutional Review Board Statement: Not applicable.

Informed Consent Statement: Not applicable.

Data Availability Statement: The data presented in this study are available on request from the corresponding author.

Acknowledgments: This research was supported by Qinzhou Key Laboratory of Biowaste Resources for Selenium-enriched Functional Utilization, Guangxi Key Laboratory of Green Chemical Materials and Safety Technology and GuangxiEngineeringResearchCenterforNew ChemicalMaterialsandSafetyTechnology. The authors acknowledge Guangxi Colleges and Universities Innovation Research Team.

Conflicts of Interest: The authors declare no conflict of interest.

\section{References}

1. Ighodaro, O.M.; Akinloye, O.A. First line defence antioxidants-superoxide dismutase (SOD), catalase (CAT) and glutathione peroxidase (GPX): Their fundamental role in the entire antioxidant defence grid. Alex. J. Med. 2018, 54, 287-293. [CrossRef]

2. Li, C.; Deng, X.; Xie, X.; Liu, Y.; Friedmann Angeli, J.P.; Lai, L. Activation of Glutathione Peroxidase 4 as a Novel Anti-inflammatory Strategy. Front. Pharmacol. 2018, 9, 1-10. [CrossRef]

3. Chang, C.; Worley, B.L.; Phaëton, R.; Hempel, N. Extracellular Glutathione Peroxidase GPx3 and Its Role in Cancer. Cancers 2020, 12, 2197. [CrossRef]

4. Xia, Y.; Hill, K.E.; Burk, R.F. Biochemical Studies of a Selenium-Deficient Population in China: Measurement of Selenium, Glutathione Peroxidase and Other Oxidant Defense Indices in Blood. J. Nutr. 1989, 119, 1318-1326. [CrossRef]

5. Loscalzo, J. Keshan disease, selenium deficiency, and the selenoproteome. N. Engl. J. Med. 2014, 370, 1756-1760. [CrossRef]

6. Toulis, K.A.; Anastasilakis, A.D.; Tzellos, T.G.; Goulis, D.G.; Kouvelas, D. Selenium Supplementation in the Treatment of Hashimoto's Thyroiditis: A Systematic Review and a Meta-analysis. Thyroid 2010, 20, 1163-1173. [CrossRef]

7. Ibrahim, S.A.Z.; Kerkadi, A.; Agouni, A. Selenium and Health: An Update on the Situation in the Middle East and North Africa. Nutrients 2019, 11, 1457. [CrossRef] 
8. Méplan, C.; Hughes, D.J. The Role of Selenium in Health and Disease: Emerging and Recurring Trends. Nutrients 2020, $12,1049$. [CrossRef]

9. Cubadda, F.; Aureli, F.; Ciardullo, S.; D Amato, M.; Raggi, A.; Acharya, R.; Reddy, R.A.V.; Prakash, N.T. Changes in Selenium Speciation Associated with Increasing Tissue Concentrations of Selenium in Wheat Grain. J. Agr. Food Chem. 2010, 58, $2295-2301$. [CrossRef] [PubMed]

10. Lara, T.S.; Lessa, J.H.D.L.; de Souza, K.R.D.; Corguinha, A.P.B.; Martins, F.A.D.; Lopes, G.; Guilherme, L.R.G. Selenium biofortification of wheat grain via foliar application and its effect on plant metabolism. J. Food Compos. Anal. 2019, 81, 10-18. [CrossRef]

11. Wang, M.; Ali, F.; Wang, M.; Dinh, Q.T.; Zhou, F.; Bañuelos, G.S.; Liang, D. Understanding boosting selenium accumulation in Wheat (Triticum aestivum L.) following foliar selenium application at different stages, forms, and doses. Environ. Sci. Pollut. Res. Int. 2020, 27, 717-728. [CrossRef]

12. Deng, X.; Liu, K.; Li, M.; Zhang, W.; Zhao, X.; Zhao, Z.; Liu, X. Difference of selenium uptake and distribution in the plant and selenium form in the grains of rice with foliar spray of selenite or selenate at different stages. Field Crop. Res. 2017, 211, 165-171. [CrossRef]

13. Gong, R.; Ai, C.; Zhang, B.; Cheng, X. Effect of selenite on organic selenium speciation and selenium bioaccessibility in rice grains of two Se-enriched rice cultivars. Food Chem. 2018, 264, 443-448. [CrossRef] [PubMed]

14. Hu, Z.; Cheng, Y.; Suzuki, N.; Guo, X.; Xiong, H.; Ogra, Y. Speciation of Selenium in Brown Rice Fertilized with Selenite and Effects of Selenium Fertilization on Rice Proteins. Int. J. Mol. Sci. 2018, 19, 3494. [CrossRef] [PubMed]

15. Zhang, H.; Zhao, Z.; Nie, B.; Lyu, C.; Liu, X. Selenium loss and changes in product quality during cooking of selenium enriched potato tubers. J. Food Compos. Anal. 2021, 96, 103728. [CrossRef]

16. Zhang, H.; Zhao, Z.; Zhang, X.; Zhang, W.; Huang, L.; Zhang, Z.; Yuan, L.; Liu, X. Effects of foliar application of selenate and selenite at different growth stages on Selenium accumulation and speciation in potato (Solanum tuberosum L.). Food Chem. 2019, 286, 550-556. [CrossRef] [PubMed]

17. Chuai, H.; Zhang, S.; Bai, H.; Li, J.; Wang, Y.; Sun, J.; Wen, E.; Zhang, J.; Xin, M. Small molecule selenium-containing compounds: Recent development and therapeutic applications. Eur. J. Med. Chem. 2021, 223, 113621. [CrossRef]

18. Köhrle, J. Selenium in Endocrinology-Selenoprotein-Related Diseases, Population Studies, and Epidemiological Evidence. Endocrinology 2021, 162. [CrossRef]

19. Yin, Y.; Wang, L.; Jin, H.; Lv, C.; Yu, S.; Huang, X.; Luo, Q.; Xu, J.; Liu, J. Construction of a smart glutathione peroxidase mimic with temperature responsive activity based on block copolymer. Soft Matter 2011, 7, 2521. [CrossRef]

20. Gao, S.; Li, T.; Guo, Y.; Sun, C.; Xianyu, B.; Xu, H. Selenium-Containing Nanoparticles Combine the NK Cells Mediated Immunotherapy with Radiotherapy and Chemotherapy. Adv. Mater. 2020, 32, 1907568. [CrossRef] [PubMed]

21. Dong, Z.; Luo, Q.; Liu, J. Artificial enzymes based on supramolecular scaffolds. Chem. Soc. Rev. 2012, 41, 7890-7908. [CrossRef] [PubMed]

22. Huang, Y.; Liu, Z.; Liu, C.; Ju, E.; Zhang, Y.; Ren, J.; Qu, X. Self-Assembly of Multi-nanozymes to Mimic an Intracellular Antioxidant Defense System. Angew. Chem. Int. Ed. 2016, 55, 6646-6650. [CrossRef]

23. Sun, T.; Zhu, C.; Xu, J. Multiple stimuli-responsive selenium-functionalized biodegradable starch-based hydrogels. Soft Matter 2018, 14, 921-926. [CrossRef] [PubMed]

24. Kazemi, M.; Akbari, A.; Sabouri, Z.; Soleimanpour, S.; Zarrinfar, H.; Khatami, M.; Darroudi, M. Green synthesis of colloidal selenium nanoparticles in starch solutions and investigation of their photocatalytic, antimicrobial, and cytotoxicity effects. Bioproc. Biosyst. Eng. 2021, 44, 1215-1225. [CrossRef]

25. Perfileva, A.I.; Nozhkina, O.A.; Tretyakova, M.S.; Graskova, I.A.; Klimenkov, I.V.; Sudakov, N.P.; Alexandrova, G.P.; Sukhov, B.G Biological Activity and Environmental Safety of Selenium Nanoparticles Encapsulated in Starch Macromolecules. Nanotechnol. Russ. 2020, 15, 96-104. [CrossRef]

26. Zhang, W.; Cheng, B.; Li, J.; Shu, Z.; Wang, P.; Zeng, X. Structure and Properties of Octenyl Succinic Anhydride-Modified High-Amylose Japonica Rice Starches. Polymers 2021, 13, 1325. [CrossRef]

27. Altuna, L.; Herrera, M.L.; Foresti, M.L. Synthesis and characterization of octenyl succinic anhydride modified starches for food applications. A review of recent literature. Food Hydrocoll. 2018, 80, 97-110. [CrossRef]

28. Mansourian, M.; Sadeghi, H.; Doustimotlagh, A.H. Activation of the Glutathione Peroxidase by Metformin in the Bile-duct Ligation induced Liver Injury: In vivo Combined with Molecular Docking Studies. Curr. Pharm. Des. 2018, 24, $3256-3263$. [CrossRef]

29. Dong, Z.; Liu, J.; Mao, S.; Huang, X.; Yang, B.; Ren, X.; Luo, G.; Shen, J. Aryl Thiol Substrate 3-Carboxy-4-Nitrobenzenethiol Strongly Stimulating Thiol Peroxidase Activity of Glutathione Peroxidase Mimic 2, 2'-Ditellurobis(2-Deoxy- $\beta$-Cyclodextrin). J. Am. Chem. Soc. 2004, 126, 16395-16404. [CrossRef]

30. Wu, Z.P.; Hilvert, D. Selenosubtilisin as a glutathione peroxidase mimic. J. Am. Chem. Soc. 1990, 112, 5647-5648. [CrossRef]

31. Pan, T.; Liu, Y.; Sun, H.; Xu, J.; Liu, J. Reversible Switch of a Selenium-Containing Antioxidant System Regulated by Protein Assembly. ACS Catal. 2020, 10, 9735-9740. [CrossRef]

32. Wang, Y.; Wang, S.; Song, R.; Cai, J.; Xu, J.; Tang, X.; Li, N. Ginger polysaccharides induced cell cycle arrest and apoptosis in human hepatocellular carcinoma HepG2 cells. Int. J. Biol. Macromol. 2019, 123, 81-90. [CrossRef] 
33. Bai, Y.; Shi, Y.; Herrera, A.; Prakash, O. Study of octenyl succinic anhydride-modified waxy maize starch by nuclear magnetic resonance spectroscopy. Carbohydr. Polym. 2011, 83, 407-413. [CrossRef]

34. Lopachin, R.M.; Gavin, T.; Geohagen, B.C.; Das, S. Neurotoxic Mechanisms of Electrophilic Type-2 Alkenes: Soft Soft Interactions Described by Quantum Mechanical Parameters. Toxicol. Sci. 2007, 98, 561-570. [CrossRef] [PubMed]

35. Prasanth, S.; Sudarsanakumar, C. Elucidating the interaction of L-cysteine-capped selenium nanoparticles and human serum albumin: Spectroscopic and thermodynamic analysis. New J. Chem. 2017, 41, 9521-9530. [CrossRef]

36. Khandsuren, B.; Prokisch, J. Preparation of red and grey elemental selenium for food fortification. Acta Aliment. 2021. [CrossRef]

37. Yan, H.; Zhengbiao, G.U. Morphology of modified starches prepared by different methods. Food Res. Int. 2010, 43, 767-772. [CrossRef]

38. Hao, Y.; Chen, Y.; Li, Q.; Gao, Q. Synthesis, characterization and hydrophobicity of esterified waxy potato starch nanocrystals. Ind. Crop. Prod. 2019, 130, 111-117. [CrossRef]

39. Song, X.; Zhu, W.; Li, Z.; Zhu, J. Characteristics and application of octenyl succinic anhydride modified waxy corn starch in sausage. Starch-Stärke 2010, 62, 629-636. [CrossRef]

40. Velásquez-Barreto, F.F.; Bello-Pérez, L.A.; Yee-Madeira, H.; Velezmoro Sánchez, C.E. Esterification and Characterization of Starch from Andean Tubers. Starch-Stärke 2019, 71, 1800101. [CrossRef]

41. Charles, A.L.; Kao, H.; Huang, T. Physical investigations of surface membrane-water relationship of intact and gelatinized wheat-starch systems. Carbohydr. Res. 2003, 338, 2403-2408. [CrossRef] [PubMed]

42. Luo, G.M.; Ren, X.J.; Liu, J.Q.; Mu, Y.; Shen, J.C. Towards more efficient glutathione peroxidase mimics: Substrate recognition and catalytic group assembly. Curr. Med. Chem. 2003, 10, 1151-1183. [CrossRef] [PubMed]

43. Dong, Z.; Liang, K.; Wang, C.; Huang, X.; Mao, S.; Li, X.; Xu, J.; Liu, J.; Luo, G.; Shen, J. A study of biomimetic system: Exploration of factors modulating the catalytic capacity of glutathione peroxidase mimics. J. Mol. Catal. A Chem. 2007, 277, 193-201. [CrossRef]

44. Damas, C.; Adibnejad, M.; Benjelloun, A.; Brembilla, A.; Carré, M.C.; Viriot, M.L.; Lochon, P. Fluorescent probes for detection of amphiphilic polymer hydrophobic microdomains: A comparative study between pyrene and molecular rotors. Colloid Polym. Sci. 1997, 275, 364-371. [CrossRef]

45. Matsui, J.; Mitsuishi, M.; Miyashita, T. Characterization of the Molecular Environment of Polymer Langmuir-Blodgett Films Using a Pyrene Fluorescent Probe. Macromolecules 1999, 32, 381-386. [CrossRef]

46. Huang, X.; Dong, Z.; Liu, J.; Mao, S.; Xu, J.; Luo, G.; Shen, J. Selenium-Mediated Micellar Catalyst: An Efficient Enzyme Model for Glutathione Peroxidase-like Catalysis. Langmuir 2007, 23, 1518-1522. [CrossRef]

47. Krystyjan, M.; Khachatryan, G.; Grabacka, M.; Krzan, M.; Witczak, M.; Grzyb, J.; Woszczak, L. Physicochemical, Bacteriostatic, and Biological Properties of Starch/Chitosan Polymer Composites Modified by Graphene Oxide, Designed as New Bionanomaterials. Polymers 2021, 13, 2327. [CrossRef] 